\title{
Crystal Morphology of Poly(3-hydroxybutyrate) on Amorphous
}

\section{Poly(vinylphenol) Substrate}

Xiaoli Sun ${ }^{1}$, Nan Gao ${ }^{1}$, Quan $\mathrm{Li}^{1}$, Jidong Zhang ${ }^{2}$, Xiaoqiu Yang ${ }^{3}$, Zhongjie Ren ${ }^{1}$, Shouke Yan ${ }^{* 1}$

1 State Key Laboratory of Chemical Resource Engineering, Beijing University of Chemical Technology, Beijing 100029, China (skyan@mail.buct.edu.cn; xiaolisun@mail.buct.edu.cn)

2 State Key Laboratory of Polymer Physics and Chemistry, Changchun Institute of Applied Chemistry, Chinese Academy of Sciences, 5625 Renmin Street, Changchun 130022, China 3 Basic Research Service, MOST, Beijing 100862, China 


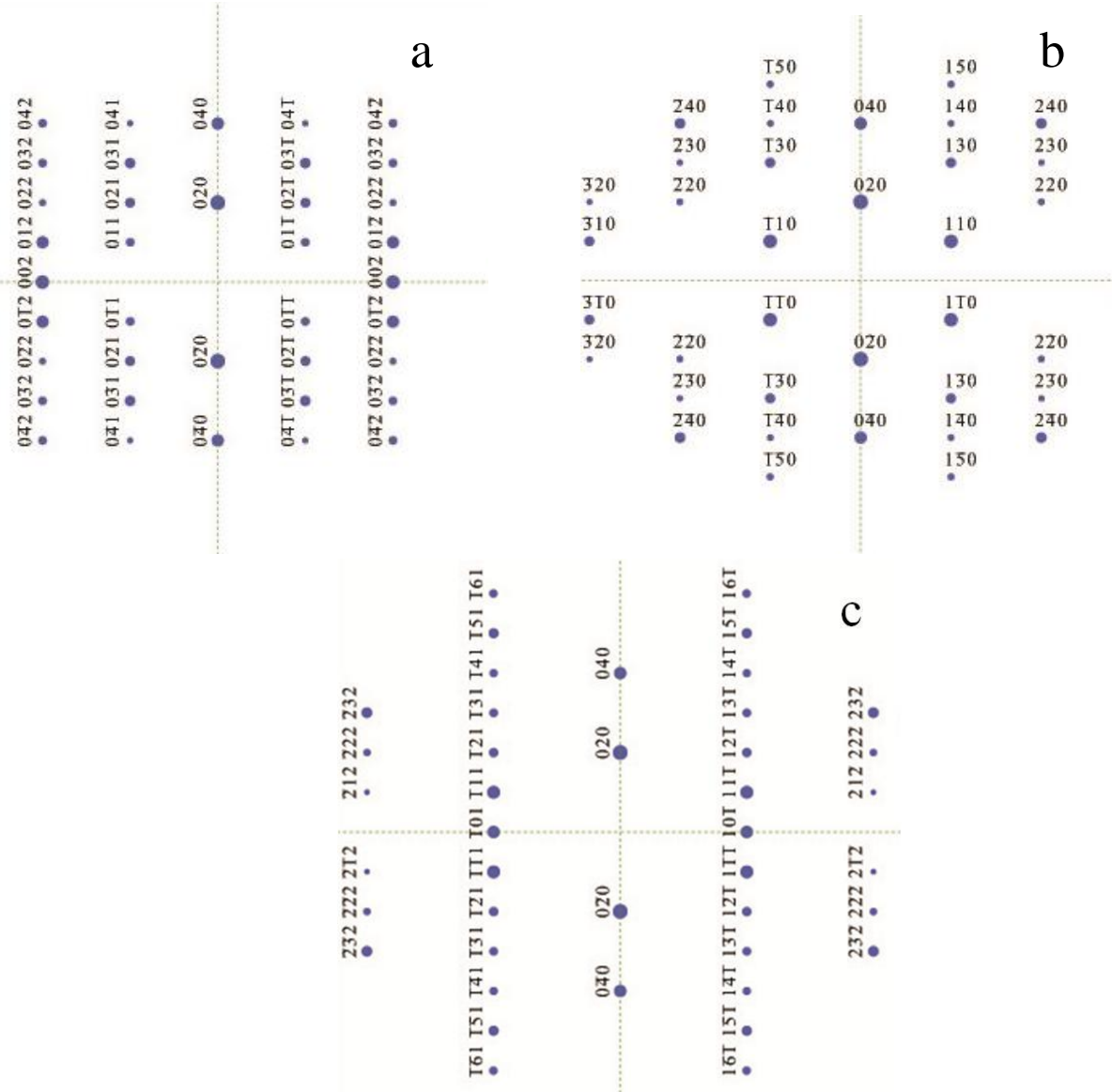

Figure S1 The simulated single crystal diffraction patterns along (a) [100], (b) [001], (c) [101]. 

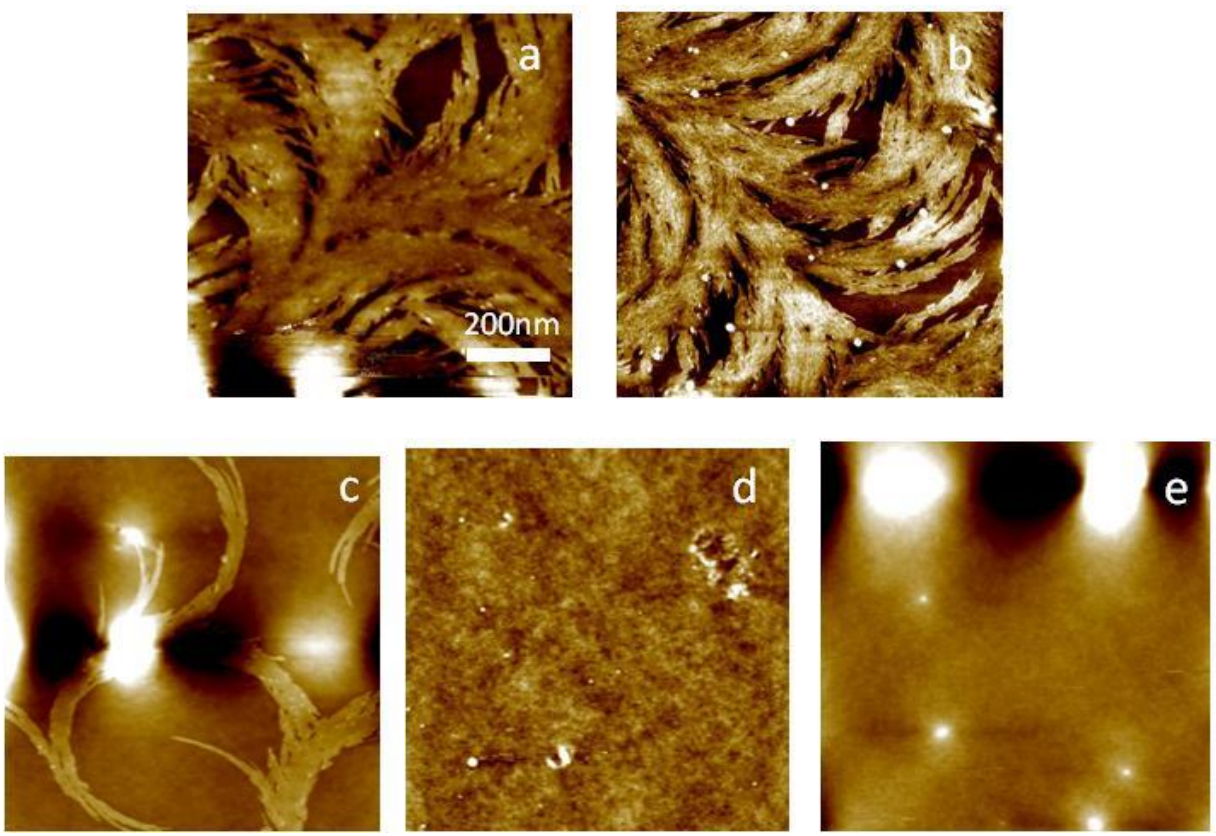

Figure S2 AFM images of the $120 \mathrm{~nm}$ thick PHB thin films on $100 \mathrm{~nm}$ thick $\mathrm{PVPh}$ melt recrystallized at (a) $25^{\circ} \mathrm{C}$, (b) $53{ }^{\circ} \mathrm{C}$, (c) $72{ }^{\circ} \mathrm{C}$, (d) $95^{\circ} \mathrm{C}$, (e) $112{ }^{\circ} \mathrm{C}$. 

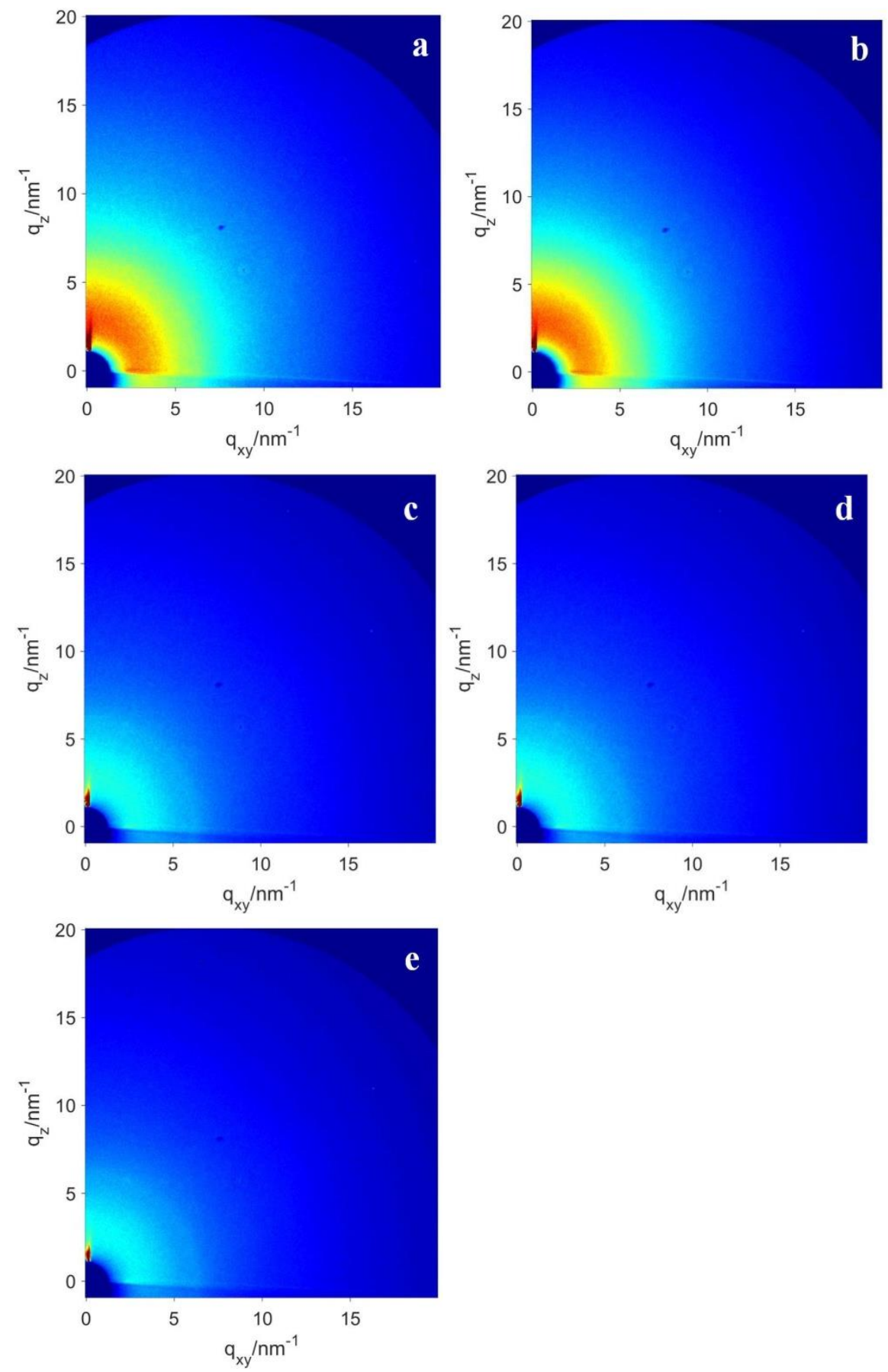

Figure S3 2D GIXD patterns of the $120 \mathrm{~nm}$ thick PHB thin films on $100 \mathrm{~nm}$ thick PVPh melt recrystallized at (a) $25^{\circ} \mathrm{C}$, (b) $53{ }^{\circ} \mathrm{C}$, (c) $72{ }^{\circ} \mathrm{C}$, (d) $95{ }^{\circ} \mathrm{C}$, (e) $112{ }^{\circ} \mathrm{C}$. 

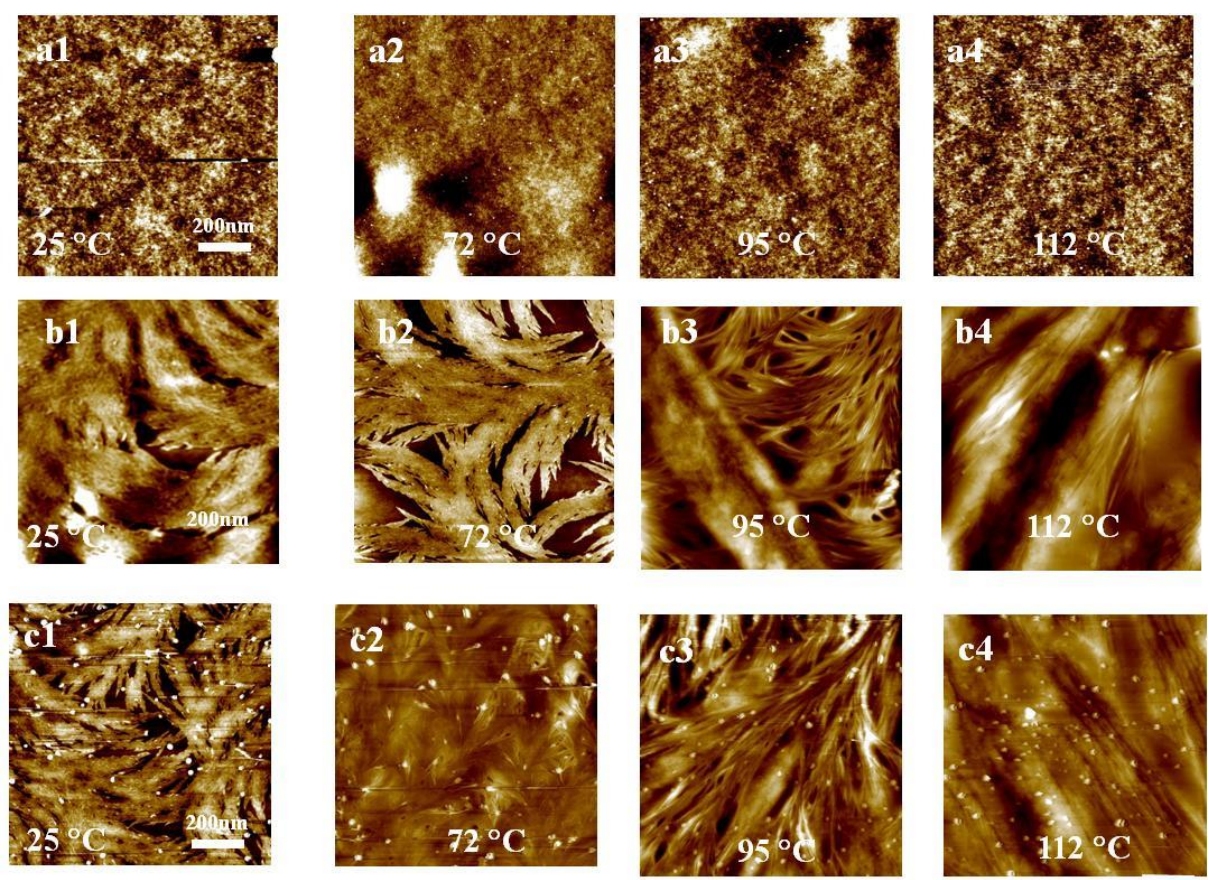

Figure S4 AFM images of (a) $105 \mathrm{~nm}$, (b) $120 \mathrm{~nm}$, (c) $138 \mathrm{~nm}$ thick PHB on $65 \mathrm{~nm}$ thick PVPh melt recrystallized at different temperatures. 